\title{
Common ways Americans are incorporating fruits and vegetables into their diet: intake patterns by meal, source and form, National Health and Nutrition Examination Survey 2007-2010
}

\author{
Latetia V Moore*, Heather C Hamner, Sonia A Kim and Karen Dalenius \\ Division of Nutrition, Physical Activity, and Obesity, National Center for Chronic Disease Prevention and Health \\ Promotion, Centers for Disease Control and Prevention, 4770 Buford Highway NE, MS F77, Atlanta, GA 30341, \\ USA
}

Submitted 22 December 2015: Final revision received 5 February 2016: Accepted 26 February 2016: First published online 28 March 2016

\begin{abstract}
Objective: We explored how Americans aged $\geq 2$ years who consumed the recommended amount of fruits and vegetables on a given day incorporated fruits and vegetables into their diet compared with those who did not consume recommended amounts.

Design: We used $1 \mathrm{~d}$ of dietary recall data from the National Health and Nutrition Examination Survey (NHANES) 2007-2010 to examine cross-sectional differences in mean intakes of fruits and vegetables in cup-equivalents by meal, source and form between the two groups.

Setting: USA.

Subjects: NHANES $2007-2010$ participants aged $\geq 2$ years ( $n$ 17571) with $1 \mathrm{~d}$ of reliable $24 \mathrm{~h}$ recall data.

Results: On a given day, the proportions of fruits and vegetables consumed at different meals were similar between those who consumed recommended amounts and those who did not. Among adults, 59-64\% of their intake of fruits was consumed at breakfast or as a snack and almost $90 \%$ came from retail outlets regardless of whether they consumed the recommended amount or not. Adults who consumed the recommended amount of fruits ate more fruits in raw form and with no additions than those who did not. Among children and adults, 52-57\% of vegetables were consumed at dinner by both groups. Retail outlets were the main source of vegetables consumed (60-68\%).

Conclusions: Our findings indicate that habits of when, where and how consumers eat fruits and vegetables might not need to change but increasing the amount consumed would help those not currently meeting the recommendation.
\end{abstract}

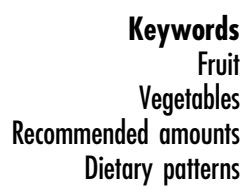

Most Americans do not eat enough fruits and vegetables ${ }^{(1)}$ in spite of the demonstrated benefits of consuming adequate amounts $^{(2)}$. The Dietary Guidelines for Americans, 2010 encourage Americans to increase their intakes of fruits and vegetables to add important nutrients that are frequently lacking from their diets, reduce the risk of many leading causes of death and illness, and aid in healthy weight management by substituting fruits and vegetables for higherenergy foods ${ }^{(2)}$. However, in 2007-2010, among individuals aged $\geq 1$ year, only approximately $13 \%$ met the age- and sex-specific vegetable intake and $25 \%$ met the age- and sex-specific fruit intake recommended in the US Department of Agriculture (USDA) Food Patterns ${ }^{(3)}$.

To date, little research has been done using nationally representative data on how people incorporate fruits and vegetables into their day ${ }^{(4-6)}$, especially among those who consume amounts recommended by the USDA Food Patterns $v$. those who do not. Given this, in the present study we explored how US children (aged 2-18 years) and adults (aged $\geq 19$ years) who consumed recommended amounts of fruits and vegetables on a given day incorporated fruits and vegetables into their diets, compared with 
those who did not, using nationally representative data from 2007 to 2010. We identified where (source), when (meal) and in what form(s) individuals consumed their fruits and vegetables among those who consumed recommended amounts on a given day $v$. those who did not.

\section{Methods}

We used data from the National Health and Nutrition Examination Survey (NHANES) 2007-2010 to estimate fruit and vegetable intakes among individuals aged $\geq 2$ years. NHANES is a nationally representative survey of the non-institutionalized US population that is conducted in two-year cycles using a stratified multistage probability design. Details on the survey and sampling are described elsewhere $^{(7)}$. Respondents participated in a household questionnaire and a physical examination, including a $24 \mathrm{~h}$ dietary recall, at the mobile examination centre (MEC). Trained interviewers collected $24 \mathrm{~h}$ dietary recalls using the USDA automated multiple-pass method by proxy for those aged $1-5$ years, with proxy assistance for those aged 6-11 years and directly from participants aged $\geq 12$ years. A total of 20686 individuals were interviewed and 20015 completed a physical examination in the MEC. MEC response rates were $75.4 \%$ and $77.3 \%$ for NHANES $2007-$ 2008 and 2009-2010, respectively. There were 17571 individuals aged $\geq 2$ years with $1 \mathrm{~d}$ of reliable $24 \mathrm{~h}$ recall data who participated in NHANES 2007-2010 and were included in analyses. All participants in NHANES provided written informed consent.

For all foods and beverages participants reported, we used USDA Food Patterns Equivalent Databases (2007-2008 and 2009-2010) to disaggregate each food and beverage item into its individual food components ${ }^{(8,9)}$. The total amounts of fruits and vegetables for each individual, in cup-equivalents, were summed across all foods and beverages that were reported. Cup-equivalents of fruits and vegetables consumed were calculated separately by the meal, source and form of each food item. Categories of meal, source and form were derived from survey responses. Of the twenty different types of eating occasion $^{(10)}$, we classified foods and beverages into five meal categories: (i) breakfast; (ii) lunch; (iii) dinner; (iv) snack; and (v) other eating occasions such as brunch and drinking occasions. Of the twenty-three different source options $^{(10)}$, we collapsed foods and beverages into four mutually exclusive categories: (i) retail (e.g. retail stores, mail order purchases); (ii) restaurants (e.g. restaurants, bars, street vendors, and sport, recreation or entertainment facilities); (iii) cafeterias (e.g. school and other institutional cafeterias, residential dining facilities, vending machines, common snack tray, childcare centre, family/adult day care centre); and (iv) other (e.g. soup kitchens or food pantries, Meals On Wheels, other community food programmes, home grown or gifted, and any other reported source). Lastly, of the sixteen different types of food and beverage combinations ${ }^{(10)}$, we collapsed foods and beverages into four mutually exclusive form categories: (i) raw/alone (e.g. whole or cut-up apple or carrots); (ii) a salad or sandwich ingredient; (iii) an ingredient in a fruit or vegetable mixed dish (e.g. salsa, hummus, tomato sauce on pizza or spaghetti); and (iv) all other forms.

Individuals were classified as consuming the recommended amounts based on the total cup-equivalents of fruits and vegetables consumed on the recall day. Recommended amounts (Table 1) ranged from 1 to 2 cup-equivalents of fruits and from 1 to 3 cup-equivalents of vegetables, were age- and sex-specific, and appropriate for individuals with less than $30 \mathrm{~min}$ of daily physical activity $^{(11,12)}$. Ratios of means were calculated to compare the relative proportions of fruits and vegetables consumed at different meals, from different sources and in different forms among those who consumed recommended amounts $v$. those who did not. Ratios of means were estimated by dividing each group's mean amount of fruit and vegetable intake from different meals, sources and forms by the group's mean total fruit and vegetable intake. Ratio of mean estimates and $P$ values for differences in the ratio of means using $t$ tests for linear contrasts were calculated using PROC RATIO in the statistical software packages SAS 9.3.2 and SAS-Callable SUDAAN 10.1 to account for the complex sampling design. Analyses were conducted separately for those aged 2-18 years and those aged $\geq 19$ years. Due to the number of statistical tests performed, a Bonferroni adjustment was used to set the significance level at 0.001.

Table 1 Intakes of fruits and vegetables, by age and sex*, recommended in the US Department of Agriculture Food Patterns

\begin{tabular}{|c|c|c|}
\hline \multirow[b]{2}{*}{ Age and sex group } & \multicolumn{2}{|c|}{ Cup-equivalents $†$} \\
\hline & Fruits $^{(11)}$ & Vegetables $^{(12)}$ \\
\hline \multicolumn{3}{|l|}{ Children } \\
\hline $2-3$ years & 1.0 & 1.0 \\
\hline $4-8$ years & $1.0-1.5$ & 1.5 \\
\hline \multicolumn{3}{|l|}{ Females } \\
\hline $9-13$ years & 1.5 & $2 \cdot 0$ \\
\hline $14-18$ years & 1.5 & 2.5 \\
\hline $19-30$ years & $2 \cdot 0$ & 2.5 \\
\hline $31-50$ years & 1.5 & 2.5 \\
\hline$\geq 51$ years & 1.5 & $2 \cdot 0$ \\
\hline \multicolumn{3}{|l|}{ Males } \\
\hline $9-13$ years & 1.5 & 2.5 \\
\hline $14-18$ years & $2 \cdot 0$ & 3.0 \\
\hline $19-30$ years & $2 \cdot 0$ & 3.0 \\
\hline $31-50$ years & $2 \cdot 0$ & 3.0 \\
\hline$\geq 51$ years & $2 \cdot 0$ & 2.5 \\
\hline
\end{tabular}

*These amounts are appropriate for individuals who get less than $30 \mathrm{~min}$ of moderate physical activity daily, beyond normal daily activities. Those who are more physically active may be able to consume more while staying within energy needs.

†One cup-equivalent is approximately equal to one small apple $(149 \mathrm{~g})$, eight large strawberries $(144 \mathrm{~g})$, twelve baby carrots $(120 \mathrm{~g})$ or one large tomato $(182 \mathrm{~g})$. 


\section{Results}

Children who consumed the recommended amounts of fruits or vegetables ate or drank about an additional cup-equivalent each of fruits and vegetables compared with those children who did not consume the recommend amounts (Table 2). Adults who consumed the recommended amounts ate or drank an additional 2.5 cup-equivalents of fruits and 2.6 cup-equivalents of vegetables compared with those who did not consume the recommended amounts.

\section{Meals}

In general, the proportions of fruits and vegetables consumed at different meals were similar between those who consumed recommended amounts and those who did not.

Table 2 Amounts of fruit and vegetables consumed by source, form and meal $v$. total intake (ratio of means) among those who met the fruit and vegetable intakes recommended by the US Department of Agriculture Food Patterns on a given day of recall $v$. those who did not meet the targets, National Health and Nutrition Examination Survey 2007-2010

\begin{tabular}{|c|c|c|c|c|c|c|}
\hline \multirow[b]{2}{*}{ Fruit } & \multicolumn{3}{|c|}{ Aged $2-18$ years: met target } & \multicolumn{3}{|c|}{ Aged $\geq 19$ years: met target } \\
\hline & Yes & No & $P$ value* & Yes & No & $P$ value* \\
\hline No. of respondents & 3244 & 2846 & & 2563 & 8918 & \\
\hline \multirow[t]{2}{*}{ Cup-equivalents consumed } & 1.7 & 0.4 & $<0.0001$ & 3.0 & 0.5 & $<0.0001$ \\
\hline & $\%$ & $\%$ & & $\%$ & $\%$ & \\
\hline \multicolumn{7}{|l|}{ Meal } \\
\hline Breakfast & 18 & 23 & 0.0116 & 25 & 34 & $<0.0001$ \\
\hline Lunch & 22 & 27 & 0.0095 & 16 & 14 & 0.0509 \\
\hline Dinner & 16 & 13 & 0.0412 & 16 & 16 & 0.8862 \\
\hline Snack & 37 & 31 & 0.0224 & 34 & 30 & 0.0021 \\
\hline Other & 8 & 6 & 0.2192 & 9 & 6 & 0.0037 \\
\hline \multicolumn{7}{|l|}{ Source† } \\
\hline Retail store/source & 80 & 72 & $<0.0001$ & 88 & 86 & 0.1956 \\
\hline Restaurant & 3 & 5 & 0.0567 & 4 & 6 & 0.0004 \\
\hline Cafeteria & 9 & 16 & $<0.0001$ & 2 & 2 & 0.8192 \\
\hline Other & 7 & 7 & 0.9453 & 7 & 6 & 0.3759 \\
\hline \multicolumn{7}{|l|}{ Form $\ddagger$} \\
\hline Raw, alone & 84 & 75 & $<0.0001$ & 82 & 70 & $<0.0001$ \\
\hline Salad or sandwich & 1 & 1 & 0.1375 & 1 & 2 & $0 \cdot 1032$ \\
\hline Fruit/vegetable mixed dished & 3 & 3 & 0.9817 & 3 & 3 & 0.6321 \\
\hline Other & 13 & 21 & $<0.0001$ & 13 & 24 & $<0.0001$ \\
\hline
\end{tabular}

Aged 2-18 years: met target

\begin{tabular}{|c|c|c|c|c|c|c|}
\hline \multirow[b]{2}{*}{ Vegetables } & & \\
\hline & Yes & No & $P$ value ${ }^{*}$ & Yes & No & $P$ value ${ }^{*}$ \\
\hline No. of respondents & 1648 & 4442 & & 1975 & 9506 & \\
\hline \multirow[t]{2}{*}{ Cup-equivalents consumed } & $1 \cdot 7$ & 0.7 & $<0.0001$ & $3 \cdot 8$ & $1 \cdot 2$ & $<0.0001$ \\
\hline & $\%$ & $\%$ & & $\%$ & $\%$ & \\
\hline \multicolumn{7}{|l|}{ Meal } \\
\hline Breakfast & 5 & 4 & 0.0698 & 7 & 5 & 0.0575 \\
\hline Lunch & 29 & 31 & 0.3129 & 28 & 31 & 0.0501 \\
\hline Dinner & 52 & 54 & 0.2198 & 57 & 56 & 0.7914 \\
\hline Snack & 14 & 11 & 0.0220 & 6 & 7 & 0.4002 \\
\hline Other & 1 & 1 & 0.9701 & 2 & 1 & 0.0444 \\
\hline \multicolumn{7}{|l|}{ Source } \\
\hline Retail store/source & 63 & 60 & 0.1541 & 68 & 62 & 0.0003 \\
\hline Restaurant & 20 & 25 & 0.0145 & 21 & 29 & $<0.0001$ \\
\hline Cafeteria & 8 & 9 & 0.3227 & 2 & 2 & 0.6792 \\
\hline Other & 10 & 6 & 0.0450 & $\overline{9}$ & 7 & 0.0019 \\
\hline \multicolumn{7}{|l|}{ Form $\neq$} \\
\hline Raw, alone & 6 & 3 & 0.0594 & 5 & 3 & 0.0006 \\
\hline Salad or sandwich & 13 & 11 & 0.1091 & 25 & 19 & $<0.0001$ \\
\hline Fruit/vegetable mixed dished & 12 & 13 & 0.5195 & 14 & 12 & 0.0614 \\
\hline Other & 69 & 73 & 0.1120 & 57 & 66 & $<0.0001$ \\
\hline
\end{tabular}

${ }^{*} P$ values for differences in the ratio of means using $t$ tests for linear contrasts.

†Stores include retail stores and mail order purchases; Restaurants include restaurants, bars, street vendors, and sport, recreation or entertainment facilities; Cafeterias include cafeterias, residential dining facilities, vending machines, common snack tray, childcare centre, family/adult day care centre; Other sources include food assistance programmes, home grown or gifted, and any other reported sources.

‡Form categories include: (i) raw and not an ingredient; (ii) an ingredient in a salad or sandwich; (iii) an ingredient in a fruit- or vegetable-based dish; and (iv) an ingredient in other types of mixed dish. Ingredient in a fruit or vegetable dish includes salsa, bean dips, guacamole and other dried bean vegetable, and fruitbased mixed dishes. 
For example, among adults, 59-64\% of fruit was consumed during breakfast or as a snack regardless of whether or not these individuals met fruit recommendations on the day of recall. However, adults who did not consume recommended amounts of fruit reported consuming a larger share during breakfast $(34 \% v$. 25\%, $P<0 \cdot 0001)$. Among all children, the largest share of fruit was consumed as a snack (31-37\%), followed by lunch (22-27\%) and then breakfast (18-23\%); however, children who consumed recommended amounts were not significantly different in their intake patterns from those who did not consume recommended amounts. For both adults and children, dinner was the meal in which the greatest proportion of vegetables was consumed (ranged from 52 to $57 \%$ ), regardless of whether they consumed recommend amounts or not.

\section{Source}

Among all adults, almost $90 \%$ of fruit was obtained from retail stores (86-88\%). Most fruit for children came from retail stores as well (72-80\%); however, cafeterias accounted for $16 \%$ of fruit intake for children who did not consume recommended amounts compared with 9\% for children who met recommendations $(P<0 \cdot 0001)$. Overall, retail stores and restaurants were the most commonly reported source for vegetables among both adults and children (retail, 60-68\%; restaurant, 20-29\%). A higher proportion of vegetables came from restaurants for adults who did not consume recommended amounts compared with adults who did meet recommendations (29\% v. $21 \%$ respectively, $P<0 \cdot 0001)$.

\section{Form}

A higher proportion of fruit was eaten raw and alone (e.g. a raw, whole or sliced apple) among adults and children who consumed recommended amounts compared with those who did not (all $P<0 \cdot 001$ ). Both adults and children consumed the majority of their vegetables in forms other than raw and alone, as part of a salad or sandwich, or in a fruit/vegetable mixed dish, regardless of meeting the recommendations. However, adults who did not consume recommended amounts also reported consuming fewer vegetables as part of a salad or sandwich (19\% v. 25\% respectively, $P<0.0001$ ) than those who consumed recommended amounts.

\section{Discussion}

In general, the proportions of fruits and vegetables consumed at different meals, from different sources and in different forms were similar between those who consumed recommended amounts and those who did not. Individuals who reported consuming recommended amounts of fruits and vegetables incorporated them into their diets in similar ways to those who did not. Compared with those who did not report consuming recommended amounts, those who did reported consuming an additional 2 cup-equivalents of both fruits and vegetables, which equated to six times as much fruit and three times as many vegetables.

The findings from the present study are consistent with prior work $^{(4-6)}$. For example, a NHANES 2007-2010 analyses indicated that about $90 \%$ of fruits and $70 \%$ of vegetables are consumed at home ${ }^{(4)}$. A survey of 2000 households in the USA indicated that two-thirds of vegetables were eaten at dinner and fruits were consumed at all eating occasions but especially breakfast (44\%) and lunch $(24 \%)^{(5)}$. Similarly, most fruits and vegetables were consumed at home and a large proportion was consumed fresh. A small-scale study among fourth to sixth graders also found that higher fruit intake was associated with starting the day with juice or fruit ${ }^{(6)}$. While the above studies have examined how small populations or subpopulations obtain fruits and vegetables and when they eat them ${ }^{(4-6)}$, the present study differs from others in that we used updated nationally representative data to explore how intakes of fruits and vegetables on a given day differed between those who consumed recommended amounts and those who did not.

Limitations of the study include reliance on the Food Patterns Equivalents Databases to estimate cup-equivalents of fruits and vegetables for each food reported. The Food Patterns Equivalents Databases disaggregate foods reported, including composite foods and mixtures, into their nutritionally relevant components and translate these amounts into cup-equivalents consistent with federal food guidance. Although the databases are uniquely designed to examine diets reported via $24 \mathrm{~h}$ recall methodology in NHANES, assumptions are made regarding the consistency of recipes and cooking methods to disaggregate foods into appropriate components. A second limitation of the analysis is that we did not examine whether usual intake of fruits and vegetables exceeded recommendations. One $24 \mathrm{~h}$ dietary recall does not capture day-to-day variation in diets and thus does not represent usual dietary intake, but is accurate for estimating differences in mean intakes as we did in these analyses $^{(13)}$. Third, individuals may not report their food consumption accurately by weight status ${ }^{(13,14)}$ and possibly between meals ${ }^{(15)}$. NHANES may under-report mean energy intake by $11 \%$ compared with total energy expenditure estimated using doubly labelled water ${ }^{(16)}$. Normal-weight adults under-reported mean energy intake by $<3 \%{ }^{(16)}$. Fruit intake estimates especially may be higher than reported given that approximately a third of fruit intake occurs as snacks. Next, while most Americans should consume more fruits and vegetables to meet recommendations, increased intake should be balanced within energy needs. Fruit and vegetable intake recommendations account for energy needs; however, individual needs may differ from those in the USDA Food Patterns. Finally, we examined patterns among children and adults overall even though fruit and vegetable intakes vary within these broad age groups ${ }^{(3)}$. 
In general, we observed no significant differences when we stratified by age in children (see online supplementary material, Supplemental Table 1) but further research may be needed to explore patterns by age.

Eating patterns by meal, source and form for those who consumed recommend amounts of fruits and vegetables on a given day $v$. those who did not were very similar and differed mainly in the amount consumed. Overall, this indicates that people may not need to shift their current habits substantially with regard to when, from where and how they eat in order to meet recommendations. Increasing the amount of fruit consumed by 1 cup-equivalent equates to eating a banana or a small apple ${ }^{(11)}$. Increasing the amount of vegetables consumed by 1 cup-equivalent equates to eating twelve baby carrots or a large tomato ${ }^{(12)}$. Small shifts in everyday eating patterns like these could help the majority of the US population who are not consuming enough fruits and vegetables reduce their risk of many leading causes of illness and death, add important nutrients to their diet, and help with weight control ${ }^{(2)}$.

\section{Acknowledgements}

Financial support: This research received no specific grant from any funding agency in the public, commercial or not-for-profit sectors. The findings and conclusions in this report are those of the authors and do not necessarily represent the official position of the Centers for Disease Control and Prevention. Conflict of interest: None. Authorship: L.V.M conceptualized the study, drafted the manuscript and performed the primary statistical analyses. S.A.K. contributed to the conceptualization of the study. H.C.H. contributed to the statistical analyses. All authors contributed to the writing of the final manuscript. Ethics of buman subject participation: This research utilized existing publicly available data and subjects cannot be identified directly or indirectly through identifiers linked to the subjects.

\section{Supplementary material}

To view supplementary material for this article, please visit http://dx.doi.org/10.1017/S1368980016000586

\section{References}

1. Krebs-Smith SM, Guenther PM, Subar AF et al. (2010) Americans do not meet federal dietary recommendations. J Nutr 140, 1832-1838
2. US Department of Agriculture \& US Department of Health and Human Services (2012) Dietary Guidelines for Americans, 2010, 7th ed. Washington, DC: US Government Printing Office.

3. National Cancer Institute, Epidemiology and Genomics Research Program (2015) Usual Dietary Intakes: Food Intakes, US Population, 2007-10. http://epi.grants.cancer. gov/diet/usualintakes/pop/2007-10/ (accessed March 2016).

4. US Department of Agriculture, Economic Researh Service (2014) Average daily intake of food by food source and demographic characteristics, 2007-10. http://www.ers.usda. gov/datafiles/Food_Consumption_and_Nutrient_Intakes/ Food_Consumption_Estimates/food_table1.xls (accessed February 2014)

5. Produce for Better Health Foundation (2010) State of the Plate: 2010 Study on America's Consumption of Fruits and Vegetables. http://www.pbhfoundation.org/pdfs/ about/res/pbh_res/stateplate.pdf (accessed February 2014).

6. Sandeno C, Wolf G, Drake T et al. (2000) Behavioral strategies to increase fruit and vegetable intake by fourth- through sixth-grade students. J Am Diet Assoc 100, 828-830

7. Zipf G, Chiappa M, Porter KS, Ostchega Y et al. (2013) National Health and Nutrition Examination Survey: Plan and Operations, 1999-2010. http://www.cdc.gov/nchs/data/ series/sr_01/sr01_056.pdf (accessed February 2016).

8. US Department of Agriculture, Agricultural Research Service (2013) Food Patterns Equivalents Database 2009-2010. http://www.ars.usda.gov/Services/docs.htm?docid=23869 (accessed February 2014).

9. US Department of Agriculture, Agricultural Research Service (2013) Food Patterns Equivalents Database 2007-2008. http://www.ars.usda.gov/Services/docs.htm?docid=23869 (accessed February 2014)

10. Centers for Disease Control and Prevention (2013) National Health and Nutrition Examination Survey: $2009-$ 2010 Data Documentation, Codebook, and Frequencies. http://www.cdc.gov/nchs/nhanes/nhanes2009-2010/DR1 IFF_F.htm\#DR1_030Z (accessed August 2014).

11. US Department of Agriculture (2016) How much fruit is needed daily? http://www.choosemyplate.gov/Fruits (accessed Febuary 2016).

12. US Department of Agriculture (2016) How many vegetables are needed? http://www.choosemyplate.gov/vegetables (accessed Febuary 2016).

13. Thompson FE \& Byers T (1994) Dietary assessment resource manual. J Nutr 124, 11 Suppl., S2245-S2317.

14. Burrows TL, Martin RJ \& Collins CE (2010) A systematic review of the validity of dietary assessment methods in children when compared with the method of doubly labeled water. J Am Diet Assoc 110, 1501-1510.

15. Poppitt SD, Swann D, Black AE et al. (1998) Assessment of selective under-reporting of food intake by both obese and non-obese women in a metabolic facility. Int J Obes Relat Metab Disord 22, 303-311.

16. Moshfegh AJ, Rhodes DG, Baer DJ et al. (2008) The US Department of Agriculture Automated Multiple-Pass Method reduces bias in the collection of energy intakes. Am J Clin Nutr 88, 324-332. 